\title{
Performance analysis of DC/DC bidirectional converter with sliding mode and pi controller
}

\author{
Chandra Shekher Purohit ${ }^{1}$, Geetha M. ${ }^{2}$, P. Sanjeevikumar ${ }^{3}$, Pandav Kiran Maroti ${ }^{4}$, \\ Shruti Swami ${ }^{5}$, Vigna K. Ramachandaramurthy ${ }^{6}$ \\ ${ }^{1,5}$ Department of Control and Automation, VIT, Vellore, TN, India \\ ${ }^{2}$ School of Electrical Engineering, VIT, Vellore, TN, India \\ ${ }^{3}$ Department of Energy Technology, Aalborg University, Esbjerg 6700, Denmark \\ ${ }^{4}$ Department of Electrical and Electronics Engineering, University of Johannesburg, South Africa \\ ${ }^{6}$ Department of Electrical Power Engineering, Universiti Tenaga Nasional, Malaysia
}

\section{Article Info}

Article history:

Received Jan 17, 2018

Revised Oct 22, 2018

Accepted Dec 3, 2018

\section{Keywords:}

Distributed power generation

Electrical vehicle

Non-isolated DC/DC converter

PI controller

Sliding mode controller

\begin{abstract}
A sliding mode controller for a non-isolated DC/DC, bidirectional converter is presented and comparative study with PI controller is done along with ISE analysis, in order to do performance analysis. The proposed system can be utilized in many applications such as electrical vehicle, distributed power generation or small grids. Second theorem of Lyapunov is utilized and stability of the closed loop system is mathematically proven. The adopted control strategy achieves effective output voltage regulation and good dynamic stability. Rejection of disturbance is also an inherent characteristic of this technique. Furthermore, it is illustrated that the system can successfully follow changes of load demand and compensates sudden disturbances in operating condition. The design is evaluated and verified using Matlab/Simulink. Results of Matlab simulation are provided to show the feasibility of the proposed system and effectiveness of control method. Simulation results show that this technique can provide a considerable edge over control techniques which are presently available (applied) over this type of converter.
\end{abstract}

Copyright $@ 2019$ Institute of Advanced Engineering and Science. All rights reserved.

\section{Corresponding Author:}

Pandav Kiran Maroti,

Department of Electrical Engineering Science,

University of Johannesburg,

B2 Lab 111, Kingsway Campus, PO Box 524 Auckland Park, Johannesburg 2006, South Africa.

Email: kiranpandav88@yahoo.co.in ${ }^{4}$, san@et.aau.dk ${ }^{3}$

\section{INTRODUCTION}

Presently, the transportation sector is mainly dependent on vehicles which use petroleum or fossil fuel as an energy source. The rate at which use of fossil fuel is increasing, it will deplete soon [1]. Uses of fossil fuel are also proven to be hazardous to the environment and causes sudden climate change. Because of the many disadvantages of fossil fuel burning and its non-availability in future, focus of researchers is shifted to find newer technologies for transportation. Battery fed electric vehicle is a promising technology in this regard. In spite of its high initial cost it is found to be most promising because of its zero carbon emission and low cost of operation.

Battery fed electrical vehicle basically takes power from a set of batteries and runs a motor for its operation. A DC/DC converter has to be used to supply power from battery or photovoltaic to load [2], [3] or motor of an electrical vehicle [4]. This paper deals with a non-isolated DC/DC bidirectional converter with Sliding Mode Control (SMC) for regulated voltage supply. Sliding mode technique is proven to be a good control technique for boost DC/DC converter [5], [6], so this paper extends the application of sliding mode controller to bidirectional converter. 
The focus area of this paper is in control of output voltage of non-isolated DC/DC bidirectional converter for both transient and steady state condition. Stepping-up and stepping down of voltage can be.

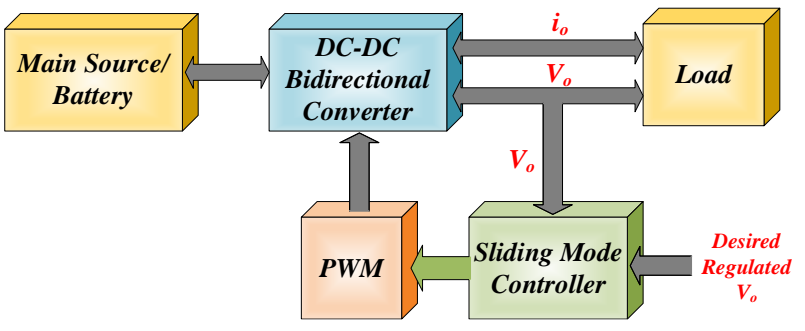

Figure 1. Block diagram proposed system

done according to the requirement of voltage. In this paper, state space averaged model of converter is represented [7] with mode of operation and sliding mode controller is designed for converter operation.

Design parameter is discussed so that the minimum required capacity of passive component can be selected [8]. The stability is analyzed by Lyapunov's theorem [9]. PI controller has been implemented to compare the result [10]-[16]. Matlab/Simulink platform is used for simulation of the system. Bidirectional DC/DC converter can be used for various applications like output voltage control, energy storage system for electric vehicle, renewable energy storage system. This converter with sliding mode control can also be used to harness energy from regenerative braking of electric vehicle.

\section{DC/DC BIDIRECTIONAL CONVERTER}

The proposed non-isolated converter can alter the output voltage in two modes. Regulation of voltage could be achieved in two ways. Firstly, it can increase the voltage by boost mode and secondly, it can decrease the magnitude of output voltage by buck mode according to the given reference value set by user. Output voltage follows reference value and the circuit topology gave inverted output voltage. In this type of converter, boost operation is followed by a buck operation so it has an analogy to buck-boost converter but with inverted output voltage. In the converter, the capacitor has been utilized for transfer of energy and same capacitor is utilized for serving the purpose of energy storage. Component of this converters is two inductors, two capacitors, one diode and one MOSFET which acts as a switch.

The DC/DC bidirectional converter with non-isolated topology can be used for electrical vehicle due its advantages such as:

a. It can work in a high efficient manner.

b. As converter topology is non- isolated type it is light in weight with compactness in size.

c. No coupling inductors are used so electromagnetic interference is quite lower than other topology.

d. It is able to control the flow of power even if there is variation in input voltage.

For better efficiency of the converter, losses of passive elements and switching losses should be minimized

\subsection{Circuit Topology}

\subsubsection{Mode of Operation}

\subsubsection{Mode $(0<\mathrm{t}<$ ton $)$}

Figure 2 shows Circuit topology of DC/DC Bidirectional converter. Figure 3 shows converter circuit during ON mode.

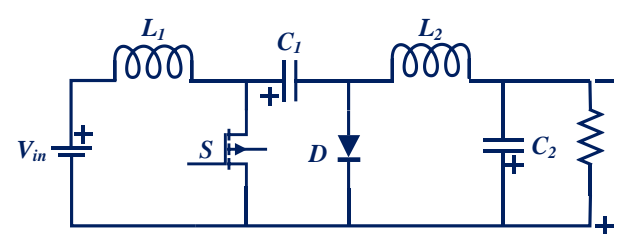

Figure 2. Circuit topology of DC/DC Bidirectional converter

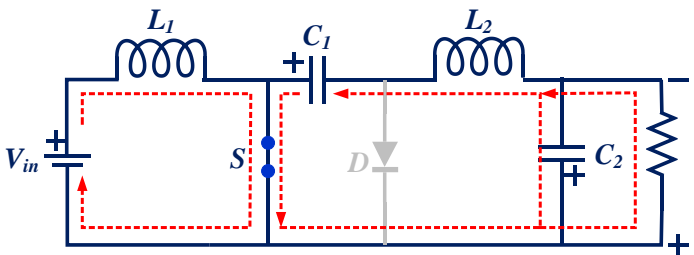

Figure 3. Converter circuit during ON mode 
For the time duration " $\mathrm{tON}_{\mathrm{ON}}$ " switch (MOSFET) is switched $\mathrm{ON}$ at $\mathrm{t}=0$ and the current flowing through inductor $L_{l}$ increases. At the same instant, diode has been reversed biased and turned OFF because of voltage stored in capacitor $C_{l}$. "toN" mode

The capacitor has to discharge its energy into the circuit formed by $C_{2}, L_{2}$ and load. Equations for

$$
\frac{d i_{L 1}}{d t}=\frac{V_{i n}}{L_{1}}
$$

$\frac{d i_{L 2}}{d t}=\frac{V_{C 1}}{L_{2}}+\frac{V_{C 2}}{C_{2}}$

$\frac{d V_{C 1}}{d t}=\frac{-i_{L 2}}{C_{1}}$

$$
\frac{d V_{C 2}}{d t}=\frac{-i_{L 2}}{C_{2}}-\frac{V_{C 2}}{R C_{2}}
$$

\subsubsection{Mode (ton $<\mathrm{t}<$ tofF $)$}

When switch (MOSFET) is turned OFF at $\mathrm{t}=\mathrm{t}_{\mathrm{on}}$, the voltage across $L_{l}$ changes its polarity in order to maintain its current uninterrupted. Higher potential is offered at anode of diode $D$, so it becomes forward bias. The passive component $C_{l}$ which is nothing, but the energy transfer capacitor is charged by input source $\mathrm{V}_{\text {in }}$ and the energy is stored in another passive component $L_{1}$. Energy stored in passive element $L_{2}$ and the energy stored in $C_{2}$ is utilized to meet the requirement of load current. The current which flows through the inductor $L_{l}$ decreases linearly during time "toFF". Figure 4 shows converter circuit during OFF mode.

$$
\begin{aligned}
& L_{1} \frac{d i_{L 1}}{d t}=V_{b 2}-V_{C 1} \\
& C_{1} \frac{d V_{C 1}}{d t}=i_{L 1} \\
& L_{2} \frac{d i_{L 2}}{d t}=-V_{0} \\
& C_{2} \frac{d V_{0}}{d t}=i_{L 2}-\frac{V_{0}}{R}
\end{aligned}
$$

State Space equation after accomplishing averaging is given by:

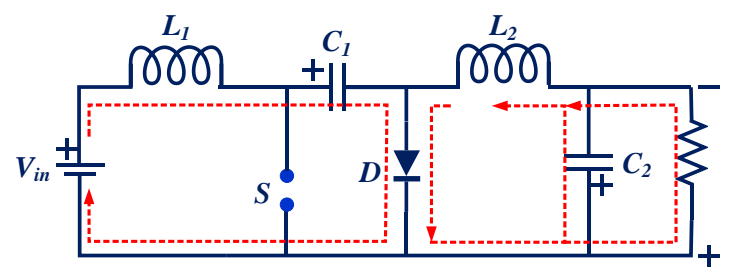

Figure 4. Converter circuit during OFF mode

$$
\begin{aligned}
& \dot{X}=A x+B u \\
& Y=C x
\end{aligned}
$$


Where,

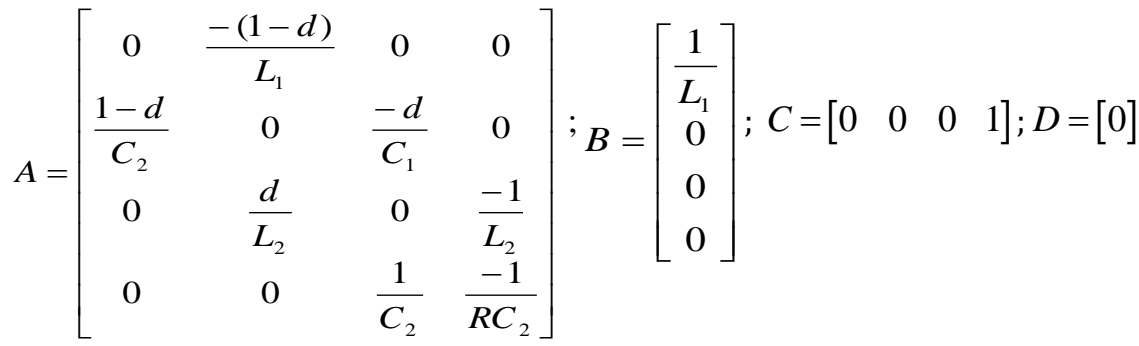

$$
\begin{aligned}
& \dot{X}=\left[\begin{array}{c}
\dot{x}_{1} \\
\dot{x}_{2} \\
\dot{x}_{3} \\
\dot{x}_{4}
\end{array}\right]=\left[\begin{array}{c}
\dot{i}_{1} \\
\dot{v}_{1} \\
\dot{i}_{2} \\
\dot{v}_{2}
\end{array}\right]
\end{aligned}
$$

\subsection{Design Parameter}

The value of two inductor $L_{1}$ and $L_{2}$ of proposed converter is calculated as

$$
\begin{aligned}
& L_{1 \min }=\frac{(1-D)}{2 D f} \\
& L_{2 \min }=\frac{(1-D) R}{2 f}
\end{aligned}
$$

The value of two capacitor $C_{1}$ and $C_{2}$ of proposed converter is calculated as

$$
\begin{gathered}
C_{1 \min }=\frac{D V_{C 2}}{V_{i n} R f} \\
C_{2 \min }=\frac{D V_{C 2}}{V_{i n} R f}
\end{gathered}
$$

\section{SLIDING MODE CONTROLLER}

Sliding mode control technique is first proposed by UKTIN [17]. This paper presents a sliding mode control method to control output voltage of converter. Sliding mode controller is a control solution for nonlinear systems. It features remarkable properties like accuracy and robustness. Sliding mode control method is a kind of varying structure control in which alteration of the dynamics of a nonlinear system is achieved by applying switching control and this switching is done at high frequency [18]-[22]. In state space current position is checked for each instant and switching is done to vary the system structure in state space from one continuous structure to another as per requirement. SMC is a control solution which can handle inaccuracies of modeling, whether it is in the form of parametric uncertainties or unstructured uncertainties. These uncertainties are handled using robust control. Sliding mode control consist of two major parts

a. Designing of sliding surface

b. Control law

\subsection{Sliding surface}

The controller is designed to force the system states to reach and remain on the pre-defined surface, which should lie in state space. The states are driven by discontinuous control to the sliding surface. When the system's state trajectory is "above" the sliding surface, one gain like '-1' will be there in feedback which will turn OFF the switch for very short duration or till it reach to reference surface and if system's state trajectory goes "below", the surface feedback path will have another gain such as ' +1 ' which will turn ON switch till it reaches at reference level [23].

Consider a general non-linear system. 


$$
\left.\begin{array}{l}
\dot{X}(t)=A(x, t)+B(x, t) u \\
Y=C x
\end{array}\right\}
$$

General form of sliding surface is given by

$$
s(x, t)=\left(\frac{d}{d t}+\lambda\right)^{(q-1)} e(t)
$$

Where, $e(t)=X_{e}-X_{\text {ref }} \mathrm{e}(\mathrm{t})$ is the error between CV and reference value, Lambda is a constant which is positive in magnitude and it is decided by the user, $q$ is called to be relative degree of the system. It can be written as

$$
s(t)=S x(t), \text { for realtive degree } 1
$$

\subsubsection{Lyapunov stability}

Lyapunov approach is used to determine the stability. A differentiable function has to be defined. Let $\mathrm{V}(\mathrm{r})$ be that function. It should be continuous and should have domain with origin. A function is said to be positive if $\mathrm{V}(0)=0$ and $\mathrm{V}(\mathrm{r})<0$ for $\mathrm{r}$. It is said to be negative definite if $\mathrm{V}(0)=0$ and $\mathrm{V}(\mathrm{r})>0$ for $\mathrm{x}$. System is called to be stable when the function is negative definite.

The stability surface for the converter is defined as

$$
S=\left\{x \mid x_{4}-k=0\right\}
$$

Variables has to be kept along sliding surface, So,

$$
x_{4}=k, \dot{x}_{4}=0
$$

Above equations when applied over equations of state space of converter

$$
\left.\begin{array}{l}
\dot{x}_{1}=\frac{1-d}{L_{1}} x_{2}+\frac{1}{L} V_{g} \\
\dot{x}_{2}=\frac{1-d}{C_{2}} x_{1}-\frac{d}{C_{2}} x_{3} \\
\dot{x}_{3}=\frac{d}{L_{2}} x_{2}-\frac{1}{L_{2}} k \\
0=\frac{1}{C_{1}} x_{3}-\frac{1}{R C_{1}} k
\end{array}\right\}
$$

To prove stability using Lyapunov's approach, a function which is continuously differentiable has to be defined. This function should be positive and definite as well.

Let $V(r)$ be that function and $V(r)$ is given by

$$
V(r)=\frac{1}{2}\left(X-X_{e}\right)^{T} p\left(X-X_{e}\right)
$$

Where, $\mathrm{k}$ is the vector representation.

$$
X=\left[\begin{array}{lll}
X_{1} & X_{2} & X_{3}
\end{array}\right]^{T}
$$

$x_{e}$ is the state variable equilibrium given by.

$$
X_{e}=\left[\begin{array}{lll}
X_{1 e} & X_{2 e} & X_{3 e}
\end{array}\right]^{t}
$$


And $\mathrm{p}$ is given by

$$
p=\operatorname{diag}\left[m_{1} \quad m_{2} \quad m_{3}\right], m_{1}, m_{2}, m_{3}>0
$$

To find out the stability of the function, the derivative of $V(r)$ must be negative definite, where,

$$
\begin{aligned}
\dot{V} r= & -(1-d)\left(\frac{m_{1}}{L_{1}}-\frac{m_{2}}{C_{2}}\right) x_{1} x_{2}+\frac{V_{b_{2}}}{L_{1}} m_{1}\left(x_{1} x_{1 e}\right) \\
& -\frac{d}{R C_{2}} k n_{2}\left(x_{2}-x_{2 e}\right)-(1-d)\left(\frac{m_{2}}{C_{2}} x_{2 e} x_{1}-\frac{m_{1}}{L_{1}} x_{1 e} x_{2}\right) \\
& +\frac{m_{3}}{L_{2}}\left(x_{3}-x_{3 e}\right)\left(d x_{2}-k\right)
\end{aligned}
$$

If $m_{1}=1000$ and $m_{2}=m_{3}=1$ are selected, $\dot{V} r$ for all $x \neq x_{e}$ is negative. Therefore, $\dot{V} r$ is negative definite function and $V(r)$ is a Lyapunov function.

\subsection{Control law}

The most tedious work is to design switch control for this system because system will be driven to sliding surface by it and will be maintained on it as well. Control law $(\mathrm{u}(\mathrm{t}))$ has two parts Nominal Control $\left(u_{n o m}\right)$ and Discontinuous Control $\left(u_{\text {dis }}\right)$, Such that

$$
u(t)=u_{n o m}+u_{d i s}
$$

The Discontinuous control will bring the state of system on the sliding surface and normal control acts as a negative feedback and it works in accordance such that system remains on sliding surface. To compute control law take derivative of equation

$$
\left.\begin{array}{l}
s(t)=S x(t) \\
\dot{s}(t)=S[A x(t)+B u(t)]
\end{array}\right\}
$$

Here $\mathrm{u}$ is defined as a feedback controller given by

$$
\mathrm{u}=-\mathrm{kx}(\mathrm{t})
$$

Where, $\mathrm{k}$ is a gain matrix which can be obtained using Pole Placement or Ackerman's formula.

$$
\dot{s}(\mathrm{t})=-\mathrm{G} \operatorname{sign}(\mathrm{S}(\mathrm{t}))
$$

Where, $\mathrm{G}$ is switching gain

$$
u(t)=S B^{-1}\left[-S A_{x}(t)-G \operatorname{sign}(S(t))\right]
$$

From (22) is the Sliding mode control law. Figure 5 shows simulation DC/DC bidirectional converter with sliding mode control. 


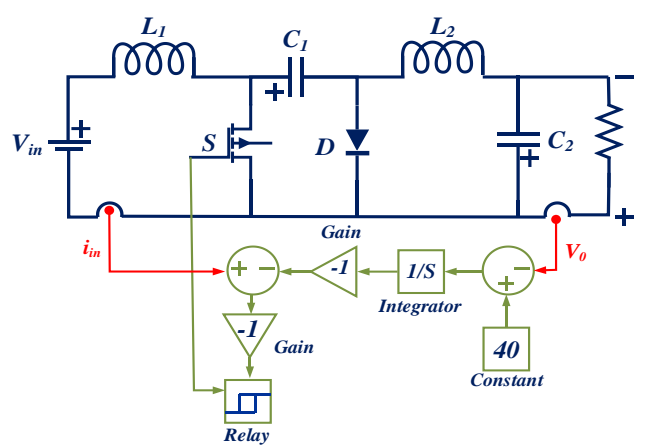

Figure 5. Simulation DC/DC bidirectional converter with sliding mode control

\section{SIMULATION RESULT AND DISCUSSION}

The Proposed bidirectional converter is simulated in Matlab R2016a with simulation parameter as articulated in Table 1.

A comparison of response of both techniques has been present for $20 \%$ load variation, for both boost and buck operating mode of converter. ISE performance analysis is also performed as shown in Table-2 which indicates that SMC is able to handle large errors as ISE value for SMC is low for both buck and boost mode. Figure 6 shows comparison of response of SMC and PI during normal operating condition.

Table 1. Specification Parameter

\begin{tabular}{lcc}
\hline \multicolumn{2}{c}{ Parameter } & Value \\
\hline \multicolumn{2}{c}{ Input Voltage (Vin) } & $75 \mathrm{~V}$ \\
\multirow{2}{*}{ Inductor } & $\mathrm{L}_{1}$ & $450 \mu \mathrm{H}$ \\
& $\mathrm{L}_{2}$ & $1.2 \mathrm{mH}$ \\
\multirow{2}{*}{ Capacitor } & $\mathrm{C}_{1}$ & $350 \mu \mathrm{F}$ \\
& $\mathrm{C}_{2}$ & $100 \mu \mathrm{F}$ \\
\hline
\end{tabular}

Table 2. ISE Analysis for Load Variation of $20 \%$

\begin{tabular}{cccc}
\hline Sr. No. & Mode of operation & SMC & PI \\
\hline 1 & Boost Mode & 0.000127 & 1.005 \\
2 & Buck Mode & $1.394 \mathrm{e}-0.5$ & 0.07161 \\
\hline
\end{tabular}

A comparison of response of both systems has been shown for both buck and boost mode of operation of the converter and ISE analysis is also performed. Table 3 shows the result of ISE analysis. Value of ISE analysis shows that SMC technique is good at handling large error as compare to PI controller. Here ISE value of SMC is much lower than PI controller for both buck and boost mode, so we can suggest that SMC is a much better technique than PI. Figure 6 shows a comparison of the response of SMC and PI for normal operating condition.

Figure 7 and Figure 8 represent a comparison of responses of PI and SMC controlled DC/DC bidirectional converter when load is varied from $20 \%$ of normal operating condition. Here in both graphs we can observe that PI controlled converter shows high oscillating while SMC controlled converter shows smooth response and also from ISE analysis, we can say that SMC is capable of handling large error. Table 3 ISE Analysis for Load Variation of 20 percent.

Figure 9 and Figure 10 Shows response of PI and SMC controlled converter when $20 \%$ parametric variation is present in converter design parameter and from the results we can say that SMC is capable of handling these kinds of uncertainties. ISE analysis shows that even under this variation SMC is able to handle large errors as compare to the PI controller with efficiency.

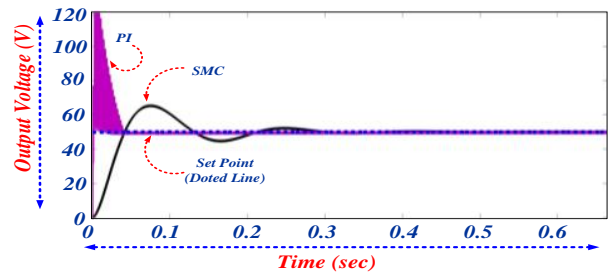

Figure 6. Comparison of response of SMC and PI during normal operating condition

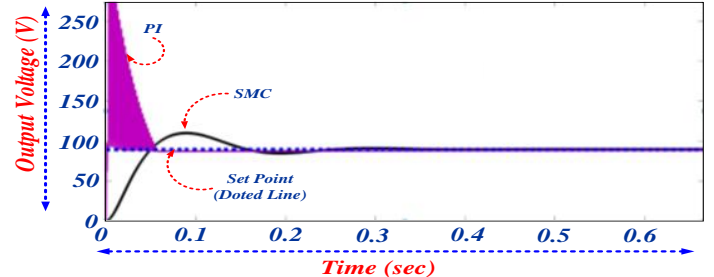

Figure 7. Comparison of response when the converter is operating in boost mode and under $20 \%$ load variation 


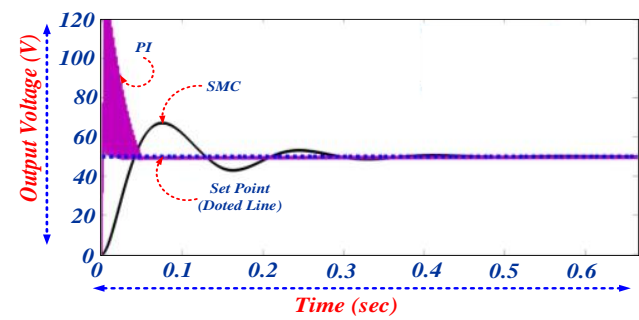

Figure 8. Comparison of response when the converter is operating in buck mode and under $20 \%$ load variation

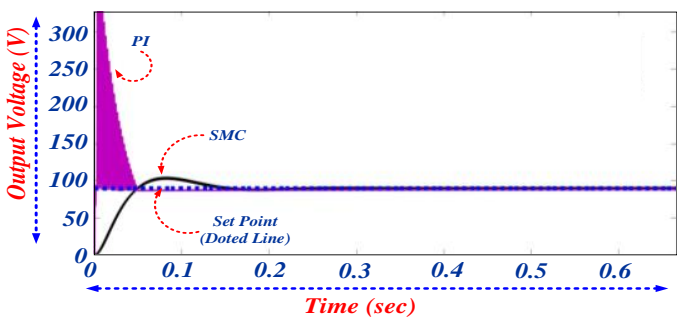

Figure 9. Comparison of response when the converter is operating in boost mode and under $20 \%$ parametric variations

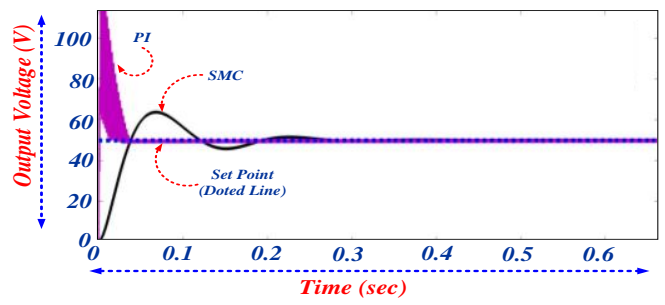

Figure 10. Comparison of response when the converter is operating in buck mode and under $20 \%$ parametric variations

Table 3. ISE analysis for load variation of 20 percent

\begin{tabular}{cccc}
\hline Sr. No. & Mode of operation & SMC & PI \\
\hline 1 & Boost Mode & $4.184 \mathrm{e}-07$ & 1.06 \\
2 & Buck Mode & $1.328 \mathrm{e}-05$ & 0.01613 \\
\hline
\end{tabular}

\section{CONCLUSION}

In this research paper, we analyzed the performances of DC/DC Bidirectional converter with two control technique SMC and PI. For performance analysis three cases are considered and those cases are normal operating condition, load variation and parameter variation. For all three cases converter is operated in two operating mode buck mode and boost mode and after analyzing all conditions, it can be inferred that SMC is a very robust technique and provides efficient control during normal operating condition and it is able to handle large error. As far as transient condition is concerned PI controller gives oscillating response, whereas SMC output does not show oscillating response which is a good feature of SMC technique but it also shows chattering phenomenon during a transient situation. Other than chattering SMC gives very smooth response and better response, stabilization than PI controller. In this paper ISE analysis is also performed to check error handling capacity and from results, it can be concluded that SMC gives very low ISE value then PI for all conditions and both operating mode (i.e. buck mode and boost mode) and hence are able to handle uncertainties as compare to PI controller for all three operating conditions and both buck and boost operating mode. Also conclude that SMC is able to work for a wide range of input and load variation as compare to PI. However, elimination of chattering and practical implication is required.

\section{REFERENCES}

[1] F. Blaabjerg, Y. Yang, K. Mam and X. Wang, "Power Electronics-The key Technology for renewable energy system Integration," Conf. Proc, 0IEEE 4th Intl. conf. on renewable Energy Research and Application, IEEEICRERA'15, 22-25 Nov, Palermo (Italy), 2015.

[2] Pandav Kiran Maroti, P. Sanjeevikumar, et al., "Multistage Switched Inductor Boost Converter For Renewable Energy Application", The 3rd IEEE Conf. on Energy Conversion (IEEE-CENCON'17), Kuala Lumpur (Malaysia), 10/2017.

[3] Pandav Kiran Maroti, P. Sanjeevikumar, et al., "Modified Boost with Switched Inductor Different Configurational Structures for DC-DC Converter for Renewable Application", IEEE 3rd Annual Southern Hemisphere Conf. on Power Electronics (IEEE-SPEC'17), Puert Varas (Chile), 12/2017. 
[4] X. S. Li, et al., "Analysis and Simplification of Three-Dimensional Space Vector PWM for Three-Phase Four-Leg Inverters," IEEE Transactions on Industrial Electronics, vol. 58, pp. 450-464, Feb 2011.

[5] Yakub Anwar Makandar and S. S. Vanamane, "Performance Analysis of Bidirectional DC-DC Converter for Electric Vehicle Application," IJIRST -International Journal for Innovative Research in Science \& Technology, Vol. 1(9), pp. 43-49, 2014

[6] F. Un-Noor, S. Padmanaban, L. Mihet-Popa, M. Mollah, and E. Hossain, "A Comprehensive Study of Key Electric Vehicle (EV) Components, Technologies, Challenges, Impacts, and Future Direction of Development," Energies, vol. 10, no. 8, p. 1217, Aug. 2017.

[7] Mohamed Derbeli, Maissa Farhat, Oscar Barambones and Lassaad Sbita, "Control of PEM fuel cell power system using sliding mode and super-twisting algorithms," Internationl journal of hydrogen Energy, vol. 42(13), pp. 8883-8844, 2017.

[8] Zengshi Chen, "PI and Sliding Mode Control of a Cuk Converter," IEEE Transactions on Power Electronics, vol. 27(8), pp.3695-3703, 2012.

[9] Simon Ang and Alejandra Oliva, "Power- Switching Converters, 2010", 3rd edition, CRC Press On one approach to the control of uncertain system, George Leitmann, Decision and Control, Proceedings of 1994 33rd IEEE Conference on Decision and Control, vol. 4, pp. 2112-2116.

[10] C. Zhao and L. Guo, "PID controller design for second order nonlinear uncertain systems", Sci. China Inf. Sci. 2017, 60:022201.

[11] P.Sanjeevikumar, G.Grandi, Frede Blaabjerg, Patrick Wheeler, Pierluigi Siano, Manel Hammami, "A Comprehensive Analysis and Hardware Implementation of Control Strategies for High Output Voltage DC-DC Boost Power Converter", International Journal of Computational Intelligence System (IJCIS), Atlantis Press and Taylor and Francis publications, vol. 10, no. 1, pp. 140-152, 2017.

[12] P. Sanjeevikumar and K. Rajambal, "Extra high voltage DC-DC boost converters with simplified control strategy", International Journal of Modeling and Simulation, Hindawi Publishing Corporation, US, vol. 2008, Article ID 593042, 8 pages, Jan. 2008. ISSN: 1697-5591, EISSN: 1687-5605.

[13] P. Sanjeevikumar, J. Kumaraguru, R. Ravi and K. Prabakaran, "Analysis of DC-DC boost converter with simplified PI controller strategy”, Conf. Proc. of National Level Power Engg. Conf., NPEC'07, Thiagarajar College of Engineering, Madurai (India), pp. 113-124, 21-22 Jun. 2007.

[14] Ramji Tiwari, N.Ramesh Babu, R.Arunkrishna and P.Sanjeevikumar, "Comparison between PI controller and Fuzzy logic based control strategies for harmonic reduction in Grid integrated Wind energy conversion system", Lecture Notes in Electrical Engineering, Springer Journal Publications, vol, 435, pp. 297-306, oct. 2017.

[15] K.Harshavardhana Reddy, P.Ramanathan, Sudha Ramasamy and P.Sanjeevikumar, "LQR PI Controller design for First order time delay systems", Lecture Notes in Electrical Engineering, Springer Journal Publications, vol, 442, pp. 405-413, oct. 2017.

[16] P.Sanjeevikumar, Frede Blaabjerg, Pierluigi Siano, Luigi Martirano, Zbigniew Leonowicz, Kiran M. Pandav, "PI and Fuzzy Control Strategies for High Voltage Output DC-DC Boost Power Converter - Hardware Implementation And Analysis", Conf. Proc. of 16 IEEE Intl. Conf. on Environment and Electrical Engg., (IEEE-EEEIC'16), Florence (Italy), 7-10 Jun. 2016.

[17] K.D.Young, V.I. Utkin, and U. Ozguner, “A control engineer's guide to sliding mode Control”, IEEE Transactions on Control System Technology, vol. 7(3), pp. 328-342, 1999

[18] P.Sanjeevikumar, Emre Ozsoy, Viliam Fedák and Frede Blaabjerg, "Development of Sliding Mode Controller for A Modified Boost Ćuk Converter Configuration”, Energies Journal, MDPI AG Publications, Switzerland, vol. 10, no. 15, pp. 1-14, 29 Sept. 2017.

[19] Eklas Hossain, Ron Perez, P.Sanjeevikumar, Frede Blaabjerg, Vigna K. Ramachandaramurthy, "Sliding Mode Controller and Lyapunov Redesign Controller to Improve Microgrid Stability: A Comparative Analysis with CPL Power Variation", Energies Journal, MDPI AG Publications, Switzerland, vol. 10, no. 1959, pp. 1-24, 24 Nov. 2017.

[20] Eklas Hossain, Ron Perez, P.Sanjeevikumar, Pierluigi Siano, "Investigation on Development of Sliding Mode Controller for Constant Power Loads in Microgrids", Energies Journal, MDPI AG Publications, Switzerland, vol. 10, no. 1086, pp. 1-24, 26 Jul. 2017.

[21] P. Sanjeevikumar, G.Grandi, Patrick Wheeler, Frede Blaabjerg and J.Loncarski, "A Simple MPPT Algorithm for Novel PV Power Generation system by High Output Voltage DC-DC Boost Converter", Conf. Proc., 24th IEEE International Symposium on Industrial Electronics, IEEE-ISIE'15, Rio de Janeiro (Brazil), pp. 214-220, 3-5 Jun. 2015.

[22] T.Anuradha, P.Deiva Sundari, P.Sanjeevikumar, Pierluigi Siano, Zbigniew Leonowicz, "Comparative Analysis of Common MPPT Techniques for Solar PV System with Soft Switched, Interleaved Isolated Converter”, IEEE 1st Industrial and Commercial Power System Europe, 17th International Conf. on Environment and Electrical Engg., IEEE-I\&CPS/IEEE-EEEIC'17, Jun. 6-9, Milan (Italy), 2017.

[23] M. H. Rashid, Power electronics Handbook, 2017; 4th edition, ELSEVIER. 